\title{
BROMELIAD-LIVING SPIDERS IMPROVE HOST PLANT NUTRITION AND GROWTH
}

\author{
Gustavo Q. Romero, ${ }^{1,4}$ Paulo Mazzafera, ${ }^{2}$ João Vasconcellos-Neto, ${ }^{1}$ and Paulo C. O. Trivelin ${ }^{3}$ \\ ${ }^{1}$ Departamento de Zoologia, Instituto de Biologia, Universidade Estadual de Campinas (UNICAMP), \\ CP 6109, CEP 13083-970, Campinas, São Paulo, Brazil \\ ${ }^{2}$ Departamento de Fisiologia Vegetal, Instituto de Biologia, Universidade Estadual de Campinas (UNICAMP), \\ CP 6109, CEP 13083-970, Campinas, São Paulo, Brazil \\ ${ }^{3}$ Divisão de Desenvolvimento de Técnicas Analiticas e Nucleares, Centro de Energia Nuclear na Agricultura (CENA/USP), \\ Universidade de São Paulo (USP), Av. Centenário 303, São Dimas, CEP 13400-970, Piracicaba, São Paulo, Brazil
}

\begin{abstract}
Although bromeliads are believed to obtain nutrients from debris deposited by animals in their rosettes, there is little evidence to support this assumption. Using stable isotope methods, we found that the Neotropical jumping spider Psecas chapoda (Salticidae), which lives strictly associated with the terrestrial bromeliad Bromelia balansae, contributed $18 \%$ of the total nitrogen of its host plant in a greenhouse experiment. In a one-year field experiment, plants with spiders produced leaves $15 \%$ longer than plants from which the spiders were excluded. This is the first study to show nutrient provisioning in a spider-plant system. Because several animal species live strictly associated with bromeliad rosettes, this type of facultative mutualism involving the Bromeliaceae may be more common than previously thought.

Key words: animal-plant interaction; Bromelia balansae; Bromeliaceae; digestive mutualism; jumping spider; nitrogen fluxes; nutrient provisioning; Psecas chapoda; Salticidae; spider-plant mutualism; stable isotope ${ }^{15} \mathrm{~N}$.
\end{abstract}

\section{INTRODUCTION}

Predators associated with plants can potentially improve plant performance by removing herbivores, as well as by provisioning host plants with nutrients derived from their debris (e.g., feces, exuviae, prey carcasses, silk). Indeed, there is considerable evidence indicating that predators can protect plants against herbivory (Schmitz et al. 2000, Romero and Vasconcellos-Neto 2004a). Although nutrient fluxes play a significant role in several animal-plant systems (e.g., Anderson and Midgley 2003, Fischer et al. 2003), very few studies have quantified the contribution of animals to plant nutrition, particularly with regard to whether the outcome of these interactions enhances plant fitness. The best known examples of animals that contribute to plant nutrition are from ant-plant systems (Huxley 1980, Rico-Gray et al. 1989, Treseder et al. 1995, Sagers

Manuscript received 19 April 2005; revised 13 October 2005; accepted 21 October 2005. Corresponding Editor: K. T. Killingbeck.

${ }^{4}$ Present address: Departamento de Zoologia e Botânica, IBILCE, Universidade Estadual Paulista (UNESP), Rua Cristóvão Colombo, 2265, CEP 15054-000, São José do Rio Preto, São Paulo, Brazil. E-mail: gq_romero@yahoo.com.br et al. 2000, Fischer et al. 2003, Solano and Dejean 2004) and from mutualistic interactions involving arthropods and insectivorous plants (Ellis and Midgley 1996, Anderson and Midgley 2003).

Plants of the large Neotropical family Bromeliaceae have their leaves organized in rosettes, an arrangement that allows them to intercept and retain debris and water (Benzing 2000) from which minerals (Benzing and Burt 1970, Benzing and Renfrow 1974, Sakai and Sanford 1980) and amino acids (Benzing et al. 1985, Owen and Thomson 1988, Endres and Mercier 2003) can be absorbed through specialized trichomes. Bromeliad rosettes are regularly inhabited by an extensive number of animal species (Benzing 1986, 2000), some of them being strongly dependent on the plant for foraging and reproduction (Benzing 2000). An example is the Neotropical jumping spider Psecas chapoda (Salticidae), which inhabits and breeds strictly on the terrestrial bromeliad, Bromelia balansae, in several regions of South America (Romero and Vasconcellos-Neto 2005a, b, c). Although nutrients derived from animal debris are assumed to fertilize Bromeliaceae (e.g., Benzing 1986, Reich et al. 2003), such benefits for plant nutrition and performance have never been demonstrated. 


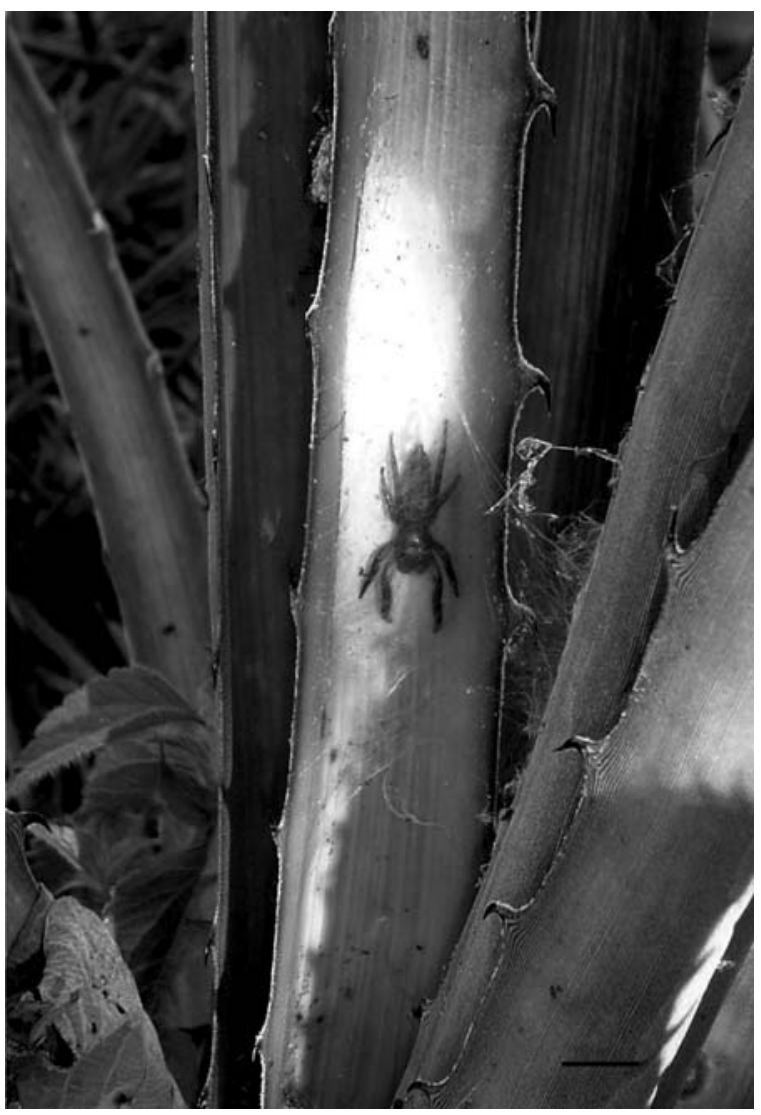

FIG. 1. Adult female jumping spider (Psecas chapoda) inside its egg sac on the concave surface of a Bromelia balansae leaf. The scale bar is $\sim 1 \mathrm{~cm}$. Photo credit: Gustavo Q. Romero.

In the present study, we used isotopic methods in greenhouse and field experiments to assess the relative contribution of the spider $P$. chapoda to nutrition in the bromeliad $B$. balansae. We addressed two main questions. (1) Does $P$. chapoda improve $B$. balansae nutrition through its debris? (2) Does B. balansae grow more when inhabited by the spiders?

\section{Methods}

\section{Study site and organisms}

The field study was done from April 2003 to June 2004 in a fragment of semideciduous forest near Dois Córregos city $\left(22^{\circ} 21^{\prime} \mathrm{S}, 48^{\circ} 22^{\prime} \mathrm{W}\right)$, São Paulo State, in southeastern Brazil. The local climate consists of a distinct dry/cold (May-September) and a wet/warm (October-April) season. Mean annual rainfall is 1600 $\mathrm{mm}$ and mean annual temperature is $21.3^{\circ} \mathrm{C}$ (Romero and Vasconcellos-Neto 2005a, b). For more details of the study area, see Romero and Vasconcellos-Neto $(2005 a, b, c)$.

Bromelia balansae is a large $(>1 \mathrm{~m}$ tall), spindlyleaved, terrestrial bromeliad common in acidic, nutrient poor cerrado (savanna-like vegetation) and semideciduous forest sites. The leaves of this semelparous bromeliad are concave with thorny margins, and do not form a tank to store water, but may retain a few milliliters of rainwater. This would allow for extended periods of nutrient dissolution and uptake by the plant leaves. In Brazil, Bolivia, and Paraguay, B. balansae is commonly inhabited by the host-specific jumping spider Psecas chapoda (Peckham \& Peckham) of the family Salticidae (see Fig. 1; Romero and Vasconcellos-Neto [2005a]). Each plant can harbor up to 20 mature and immature spiders (Romero and Vasconcellos-Neto $2005 c$ ). The entire life cycle of $P$. chapoda, including courtship behavior, mating, oviposition, and spiderling recruitment, occurs on the bromeliad $B$. balansae (Rossa-Feres et al. 2000, Romero and VasconcellosNeto $2005 a, b, c)$.

\section{Greenhouse experiment: nitrogen fluxes from spiders to plants}

The contribution of spiders to the nutrition of $B$. balansae was investigated in the laboratory using debris obtained from spiders fed with isotopically labeled Drosophila melanogaster flies. The flies were cultured from eggs in a medium of agar, corn meal, glucose, minerals, and ${ }^{15} \mathrm{~N}$-labeled yeast. The labeled yeast was obtained by raising commercial yeast on a Difco-Bacto carbon-based medium with $80 \%$ nonlabeled $\left({ }^{14} \mathrm{NH}_{4}\right)_{2} \mathrm{SO}_{4}$ (which could contain some ${ }^{15} \mathrm{~N}$ atoms at natural abundance level) and $20 \%$ labeled $\left({ }^{15} \mathrm{NH}_{4}\right)_{2} \mathrm{SO}_{4}$ (98 atom \% excess, from Cambridge Isotope Laboratories, Andover, Massachusetts, USA).The yeast was cultured in sterile tubes at $30^{\circ} \mathrm{C}$ for $54 \mathrm{~h}$ (Schlenck and De Palma 1957) and was concentrated by centrifugation, frozen, lyophilized, and incorporated into the Drosophila medium.

To obtain spider feces and fly carcasses, 17 adult females of $P$. chapoda were maintained individually in glass jars ( $7 \mathrm{~cm}$ diameter, $11 \mathrm{~cm}$ high) in the laboratory and were fed 15 flies every second day. This time interval was enough for the spiders to kill all of the flies and produce feces. At two-day intervals, the spider feces and carcasses of consumed flies were collected, lyophilized, weighed, and stored individually in polypropylene tubes. In addition, at two-day intervals over the experiment, 15 flies were collected from the culture bottles and received the same treatments of the feces and carcasses. The feces were collected from the jars using a micropipette and were suspended in distilled water $(150 \mu \mathrm{L})$. Depending upon the treatment, the feces, dead flies, or carcasses were deposited in the center of the rosettes of five bromeliads at two-day intervals over 48 days (from 17 February to 4 March 2004). The leaves were collected on 11 March 2004 for ${ }^{15} \mathrm{~N}$ and $\mathrm{N}$ determinations. The bromeliads were automatically watered (fine spray) for 5 minutes every 8 hours. This amount of water was not sufficient to remove spider debris from the pots because water did not accumulate in the plastic dish under each pot. The bromeliads were of the same cohort and were grown from seeds in pots containing homogeneous soil 
from the study area. Before this experiment, the plants had grown in a greenhouse for $\sim 2.5$ years and had no contact with spiders.

The potted bromeliads were small and similar in size (older leaf length $\sim 30 \mathrm{~cm}$ ) to plants in the field that supported up to two adult spiders (Romero and Vasconcellos-Neto 2005c). A previous bioassay showed that adult $P$. chapoda females feed on 15-20 flies per day and produce feces continually. We surveyed and processed the leaves as previously described.

\section{Field experiment: spider exclusion and plant growth}

To examine the effect of spiders on plant growth, we planted bromeliads from the same cohort of those used in the greenhouse experiment in pots $(25 \mathrm{~cm}$ diameter, $18 \mathrm{~cm}$ high) containing homogeneous soil. Before this experiment, the plants had grown in a greenhouse for $\sim 2.5$ years and had no contact with spiders. We used 16 bromeliads in each of two treatments that included plants naturally colonized by spiders (experimental group) and plants from which spiders were excluded (control group). Each bromeliad was placed on a threelegged iron support to avoid root contact with soil from the field. The legs of the control supports periodically received $10-\mathrm{cm}$ barriers of Tanglefoot resin (Tanglefoot, Grand Rapids, Michigan, USA) to prevent colonization by spiders. The supports of both treatments were fixed in the soil through their legs and the plants were raised 20 $30 \mathrm{~cm}$ above ground level. The supports of plants that were to be colonized by spiders did not receive resin and were positioned so that the leaf tips touched B. balansae plants from the natural population to allow colonization by spiders. The control plants were randomly positioned within $1-2 \mathrm{~m}$ of naturally growing $B$. balansae plants and $\sim 0.5-2 \mathrm{~m}$ from plants colonized by spiders. The plants were watered once a week $(\sim 0.5 \mathrm{~L} /$ week $)$ throughout the experiment and were inspected at twoweek intervals; any spider found on the control plants was removed. One new (second node) and one mature leaf (fourth or fifth node) were marked with a fine colored wire; we measured their length prior to the beginning of the experiment (May 2003), and then every three months for one year (May 2004). We also counted the number of leaves per rosette throughout the experiment. Leaf length and number of leaves were the most appropriate measurements to estimate plant growth in this study. For other measurements, such as leaf surface area or leaf biomass, the leaves should be removed or excessively handled (e.g., estimation of leaf width at the base) to obtain accurate data. However, these destructive methods probably could affect the plant growth and/or cause disturbance and drive the spiders to abandon the plants. Herbivory was undetectable during the experiment. All of the plants in the experimental group were rapidly colonized by spiders, as in a previous field experiment (Romero and Vasconcellos-Neto 2005a).
At the end of the experiment (May 2004), two new leaves were collected from each experimental and control rosette and prepared (as described previously) for isotopic analysis.

The data on leaf length and the number of leaves of plants with and without spiders were $\log _{10}$-transformed for normalization and homogenization of the variances (Sokal and Rohlf 1995). The data were then compared by repeated-measures analyses of covariance (ANCOVA) in a completely randomized design (Hurlbert 1984) in which treatment was a fixed effect, time was the repeated factor, and the initial measure was the covariate (Sokal and Rohlf 1995).

\section{Isotopic analyses}

The ${ }^{15} \mathrm{~N}$ atom $\%$ and $\delta{ }^{15} \mathrm{~N}\left(=\left(\left[{ }^{15} \mathrm{~N}:{ }^{14} \mathrm{~N}_{\mathrm{sam}} /{ }^{15} \mathrm{~N}:{ }^{14} \mathrm{~N}_{\mathrm{std}}\right]\right.\right.$ $-1) \times 1000$, where "sam" is the sample ratio and "std" is the standard ratio) of the bromeliad leaves, spider feces, carcasses, flies, and spiders (natural abundances and enriched) were determined using an Elemental Analyzer ANCA-SL (Automatic Nitrogen and Carbon Analyzer, Europa Scientific, Crewe, UK) with a magnetic sector of low resolution, coupled to a mass spectrometer (IRMS 20-20, Europa Scientific, Crewe, UK).

The calculation to determine the fraction of plant $\mathrm{N}$ derived from labeled spider feces and carcasses was done based on APE (atom percent ${ }^{15} \mathrm{~N}$ excess), through the following equation:

$$
\% \mathrm{~N}_{\mathrm{dfspider}}=\left(\frac{\mathrm{APE}_{\mathrm{Bb}}}{\mathrm{APE}_{\mathrm{fec}}}\right) \times 100
$$

where $\mathrm{APE}_{\mathrm{Bb}}\left(\mathrm{APE}_{\mathrm{Bb}}=\mathrm{AP}_{\mathrm{Bb}}-\mathrm{AP}_{\mathrm{con}}\right)$ and $\mathrm{APE}_{\mathrm{fec}}$ $\left(\mathrm{APE}_{\mathrm{fec}}=\mathrm{AP}_{\text {fec }}-\mathrm{AP}_{\text {con }}\right)$ are the mean atom \% excess values for B. balansae ("Bb") leaves that received labeled feces or carcasses, and for feces ("fec"), respectively, where "con" is control. AP is the mean atom percent value for each sample. The values of atom percent ${ }^{15} \mathrm{~N}$ for the labeled bromeliad leaves, feces, carcasses, flies, and spiders are given in Table 1 .

\section{HPLC and other analyses}

To determine the $\mathrm{N}$-containing compounds in spider feces, the feces of five adult female spiders were diluted in distilled water ( $\mathrm{pH} 7.5$ ), passed through $0.2-\mu \mathrm{m}$ filters, and analyzed by reversed-phase high-performance liquid chromatography (RP-HPLC). The compounds were separated on a Supelco $\mathrm{C}_{18}$ column $(5 \mu \mathrm{m}, 4 \times 250$ $\mathrm{mm}$; Sigma-Aldrich, St. Louis, Missouri, USA) using aqueous $0.5 \mathrm{~mol} / \mathrm{L}$ sodium acetate as the solvent at a flow rate of $0.8 \mathrm{~mL} / \mathrm{min}$. The compounds that eluted from the column were monitored with a diode array detector operating at 190-340 nm. Pure hypoxanthine, uric acid, urea, adenine, and guanine were used to construct a calibration curve to determine the concentration in the samples.

Samples of soil from near the roots and samples of green leaves from $B$. balansae growing in the field were tested for the presence of microorganisms having an ability to degrade guanine. Soil ( $n=51$-g samples) and 
TABle 1. Atom $\%{ }^{15} \mathrm{~N}$ values (mean, with $\mathrm{SE}$ in parentheses) for the leaves of greenhouse-grown individuals of Bromelia balansae (enriched vs. control), and for unenriched vs. enriched ( $\sim 20 \%$ atom percent excess) spider feces, Drosophila melanogaster carcasses left by spiders, intact $D$. melanogaster flies, and adult spiders.

\begin{tabular}{lcr}
\hline \hline \multicolumn{1}{c}{ Treatment } & Atom $\%{ }^{15} \mathrm{~N}$ & $N$ \\
\hline Greenhouse experiment & & \\
Treatment 1, feces & $1.558(0.08)$ & 5 \\
Treatment 2, dead flies & $1.151(0.17)$ & 5 \\
Treatment 3, carcass & $0.684(0.04)$ & 5 \\
Control & $0.370(0.00)$ & 5 \\
Feces & & \\
Unenriched & $0.3707(0.37)$ & 3 \\
Enriched & $8.395(0.60)$ & 4 \\
D. mel. carcasses, enriched & $11.805(0.66)$ & 4 \\
Drosophila melanogaster & & \\
Unenriched & $0.3674(0.01)$ & 2 \\
Enriched & $13.643(0.80)$ & 4 \\
Spiders (adult females) & & \\
$\quad$ Unenriched & 0.3728 & 4 \\
Enriched & $3.036(0.63)$ & \\
\hline
\end{tabular}

Notes: Nitrogen uptake was determined in a greenhouse by applying ${ }^{15} \mathrm{~N}$-enriched spider feces (treatment 1 ), ${ }^{15} \mathrm{~N}$-enriched dead $D$. melanogaster flies (treatment 2), and D. melanogaster carcasses discarded by spiders (Psecas chapoda) after feeding (treatment 3 ) in two-day intervals over 48 days. $N$ is the number of replicates.

green leaves $(n=2)$ from two plants were vigorously shaken in $50 \mathrm{~mL}$ of distilled water for $12 \mathrm{~h}$ and $0.5 \mathrm{~h}$, respectively. We then spread $100-\mu \mathrm{L}$ aliquots on minimum solid medium (Sambrook et al. 1989) containing guanine as the only source of carbon and nitrogen. The medium was maintained for $72 \mathrm{~h}$ at $30^{\circ} \mathrm{C}$.

\section{Results}

Our laboratory manipulations indicated that Drosophila flies, the spiders that fed on these flies, and their feces were strongly ${ }^{15} \mathrm{~N}$ enriched (Table 1 ). The greenhouse experiment showed that the values of atom $\%{ }^{15} \mathrm{~N}$ for leaves were higher after treatment with feces (feces $>$ dead flies $>$ carcasses $>$ control; ANOVA/LSD (least significant difference) Fisher post hoc test; Table 1), indicating that feces were more important than entire dead insects and discarded insect carcasses as a source of plant $\mathrm{N}$. During this experiment (48 d), we determined through Eq. 1 that spider feces, dead flies and carcasses contributed $15 \%, 6 \%$, and $3 \%$, respectively, of the total $\mathrm{N}$ of $B$. balansae. Therefore, the total spider activity contributed $18 \%$ (feces + carcasses) of the total $\mathrm{N}$ of the bromeliads.

In the field experiment, new leaves of bromeliads grew $15 \%$ longer in the presence of spiders than in their absence $(P=0.023$; Fig. 2 A, Table 2$)$. The $\delta^{15} \mathrm{~N}$ values of leaves from bromeliads with spiders were also significantly higher than in leaves of bromeliads from which spiders were excluded (for spiders present, $\delta^{15} \mathrm{~N}=$ $3.21 \pm 0.33 \%$ [mean $\pm \mathrm{sE}], n=16$; for spiders absent, $\delta^{15} \mathrm{~N}=1.88 \pm 0.34 \%, n=16$; Mann-Whitney, $P=$ $0.006)$. The length of the mature leaves and the number of leaves produced by the bromeliads in the absence and presence of spiders did not differ statistically $(P \geq 0.06$; Fig. 2B and C, Table 2). The reduction in the number of green leaves in the bromeliads without spiders at sampling date 2 (Fig. 2C) was probably caused by the increase in frequency of older (green) leaves that died; dead leaves were not counted in this experiment.

Using HPLC, we verified that guanine was the most abundant $\mathrm{N}$-containing compound found in the feces of P. chapoda $(35.2 \pm 1.60 \mu \mathrm{g} /$ feces, mean $\pm \mathrm{sE} ; n=5)$, although traces of uric acid and hypoxanthine were also detected. Bacteria obtained from leaves and soil all grew in guanine-enriched medium, but were more numerous in the soil. More than 100 colonies picked up from the soil samples also grew when replicated onto fresh medium.
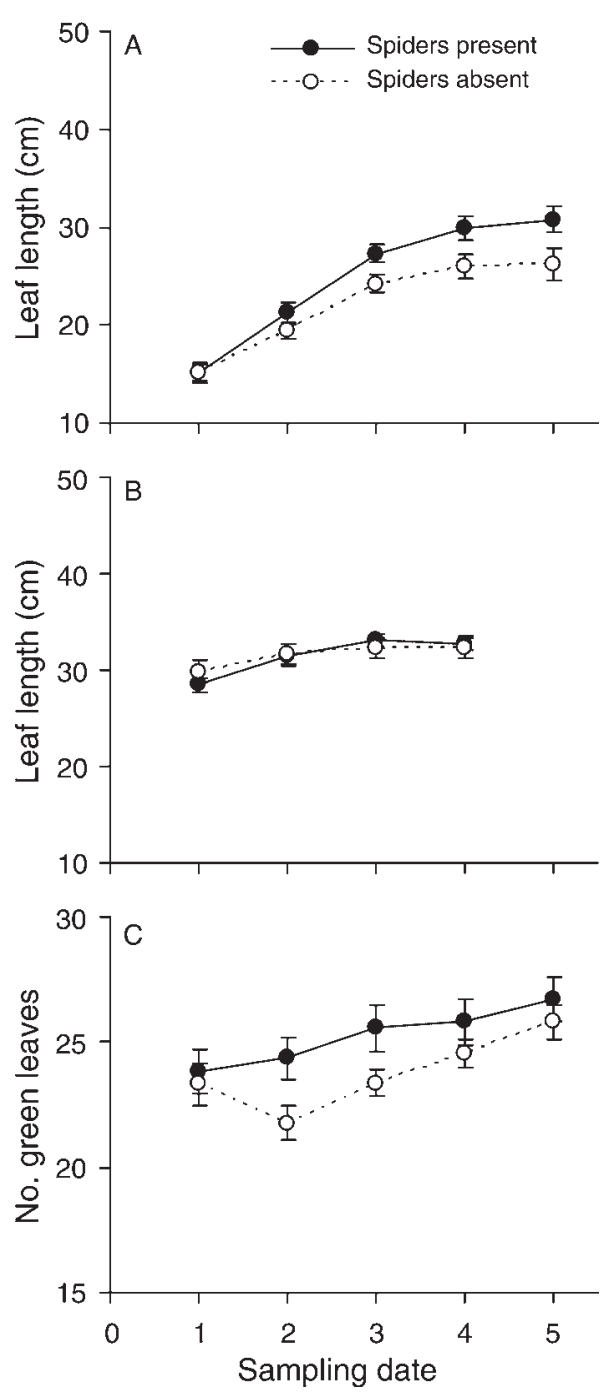

FIG. 2. Field experiment showing (A) the growth of new leaves, (B) the growth of mature leaves, and (C) leaf production in Bromelia balansae in the absence (open circles) and presence (filled circles) of jumping spiders. Sampling date codes are: 1, 10 May 2003; 2, 1 August 2003; 3, 4 November 2003; 4, 10 February 2004; 5, 1 May 2004. 
TABLE 2. Repeated-measures ANCOVA of the field experiment examining effects of the presence of $P$. chapoda spiders on leaf growth and leaf production in $B$. balansae.

\begin{tabular}{lrcrrr}
\hline \hline Source of variation & df & MS & $F$ & $P$ & G-G \\
\hline Growth of new leaves & & & & & \\
$\quad$ Spider & 1 & 0.081 & 5.95 & 0.023 & \\
$\quad$ Pretreatment & 1 & 0.022 & 1.63 & 0.215 & \\
Error & 22 & 0.014 & & & \\
Time & 3 & 0.045 & 31.36 & $<0.001$ & $<0.001$ \\
Time $\times$ spider & 3 & 0.002 & 1.35 & 0.265 & 0.267 \\
Time $\times$ pretreatment & 3 & 0.034 & 23.77 & $<0.001$ & $<0.001$ \\
Error & 66 & 0.001 & & & \\
Growth of mature leaves & & & & & \\
Spider & 1 & 0.010 & 3.93 & 0.058 & \\
Pretreatment & 1 & 0.141 & 56.77 & $<0.001$ & \\
Error & 27 & 0.002 & & & \\
Time & 2 & 0.002 & 4.47 & 0.016 & 0.033 \\
Time $\times$ spider & 2 & 0.000 & 0.41 & 0.670 & 0.579 \\
Time $\times$ pretreatment & 2 & 0.002 & 4.15 & 0.021 & 0.040 \\
Error & 54 & 0.000 & & & \\
No. green leaves & & & & & \\
$\quad$ Spider & 1 & 0.013 & 2.72 & 0.111 & \\
Pretreatment & 1 & 0.124 & 25.53 & $<0.001$ & \\
Error & 27 & 0.005 & & & \\
$\quad$ Time & 3 & 0.003 & 3.86 & 0.018 & 0.012 \\
Time $\times$ spider & 3 & 0.003 & 3.09 & 0.040 & 0.031 \\
Time $\times$ pretreatment & 3 & 0.003 & 3.17 & 0.037 & 0.029 \\
Error & 81 & 0.001 & & & \\
& & & & &
\end{tabular}

Notes: The first measure (pretreatment) was used as the covariate. G-G is the Greenhouse-Geisser epsilon correction.

\section{Discussion}

Our findings strongly support the hypothesis that Bromelia balansae can incorporate nutrients excreted by associated predators. In the greehouse experiment (48 d), the spider feces and prey carcasses together contributed $18 \%$ of the total $\mathrm{N}$ of the bromeliads. However, in nature the spider contribution is likely to be even greater because additional N-rich debris produced by Psecas chapoda (e.g., silk from egg sacs, dead eggs, exuviae) may help to improve plant nutrition. In addition, spider debris can be continually accumulated inside the bromeliad rosettes through several years.

In contrast to carnivorous bromeliads (e.g., Brocchinia reducta) that produce odors, morphological traits, and enzymes to attract, capture, and digest insect prey (Givnish et al. 1984, Benzing 2000), respectively, B. balansae shows no obvious adaptive feature for directly obtaining animal nutrients. In addition, in contrast to many bromeliad rosettes that form phytotelmata and are therefore considered to be saprophytic (Benzing 2000), B. balansae does not form phytotelmata. However, this plant has large thorns in the leaf margins and an architecture that provides shelter against predators and fire, foraging and reproductive sites, as well as nurseries, for $P$. chapoda, all of which strengthen the fidelity of this predatory partnership (Romero and Vasconcellos-Neto 2005a, b, c). The spiders contribute to host plant nutrition indirectly by capturing and digesting prey in a manner analogous to that of carnivorous plants and, through their debris, concentrate nutrients inside the rosettes. Hence, in this case, plant nutrition derived from animals can occur even in the absence of carnivorous or saprophytic habits (see Anderson and Midgley 2003). According to Anderson and Midgley (2003), digestive mutualisms (i.e., mutualisms involving arthropods that contribute to plant nutrition) only substitute for digestive organs in plants if they are obligate and host specific (Anderson and Midgley 2003). In this regard, $P$. chapoda is highly specific to $B$. balansae, and this spider-plant association is very common in several regions of cerrado (savannalike vegetation) and semideciduous forests in South America (Rossa-Feres et al. 2000, Romero and Vasconcellos-Neto 2005a, b, c; G. Q. Romero, unpublished data). However, our field experiments showed that $B$. balansae can survive in the absence of spiders, suggesting that this mutualism may be facultative.

Although absorptive trichomes are more abundant on the leaves of $B$. balansae than on other terrestrial, rootbased bromeliads, and can absorb minerals (Benzing and Burt 1970), they are probably unable to absorb amino acids (Benzing et al. 1976). Because the $\mathrm{N}$ compounds excreted by $P$. chapoda spiders (e.g., guanine) are simpler than some amino acids, they might be incorporated directly through the trichomes. In addition, the larger amino acids and other complex organic molecules (e.g., insect carcass) may possibly be mineralized by bacteria (and perhaps other microorganisms) found on the leaves and roots of B. balansae. In the notorious mutualisms involving phytotelm bromeliads and associated microorganisms (e.g., bacteria), the saprophytic plants intercept litter and the symbionts decompose and mineralize the phytomass, which becomes available for uptake by the plant (Benzing 2000). Bacteria are also present in insectivorous plants and are probably associated with prey digestion (see Anderson and Midgley 2003). The bacteria found in this study may constitute a third component that corresponds to a second-order mutualist in this spider-plant system.

Because the soils where B. balansae lives (e.g., South American savannas) are typically poor and acidic (Oliveira and Marquis 2002), spider-supplied N could provide a major benefit to this plant species. Indeed, our field experiment showed that, in the presence of spiders, new leaves grew longer than those of plants without spiders. Several groups of animals, including other jumping spider species, are strictly associated with bromeliads, where they hide, forage, and reproduce (Benzing 2000, Machado and Oliveira 2002, Romero and Vasconcellos-Neto 2004b, 2005a, b). These animals can potentially fertilize their host plants with fecal remains and other debris. Although there are several examples of animals that contribute to plant nutrition (Huxley 1980, Rico-Gray et al. 1989, Treseder et al. 1995, Ellis and Midgley 1996, Sagers et al. 2000, Anderson and Midgley 2003, Fischer et al. 2003, Solano and Dejean 2004), to our knowledge, this is the first 
study to document digestive mutualism in the Bromeliaceae and between spiders and plants, and to simultaneously show that animals can improve plant growth by affecting nutrition through their debris.

Terrestrial bromeliads without phytotelmata, such as B. balansae, are assumed to depend on the soil for nutrient acquisition (Benzing 1986, Endres and Mercier 2003) and to be better adapted to absorb and assimilate inorganic N. In contrast, tank-bromeliads, especially those with epiphytic habits, are better adapted to use organic N (Owen and Thomson 1988, Endres and Mercier 2001) and are probably more dependent on vegetation and faunal debris for nutrition (Benzing 1986). This observation suggests that tank-bromeliads may benefit even more from animal nutrient input than do terrestrial bromeliads such as B. balansae.

\section{ACKNOWLEDGMENTS}

We thank D. H. Benzing, W. W. Benson, H. Mercier, K. Killingbeck, and three anonymous referees for valuable comments on the manuscript, and A. E. B. Romero for help with data collection. The staff of Guedes farm kindly provided permission to work on their property. G. Q. Romero was supported by a research grant from Fundação de Amparo à Pesquisa do Estado de São Paulo (FAPESP, grant 01/04610-0). J. Vasconcellos-Neto was supported by a grant from Conselho Nacional de Desenvolvimento Científico e Tecnológico (CNPq, grant 300539/94-0).

\section{Literature Cited}

Anderson, B., and J. J. Midgley. 2003. Digestive mutualism, an alternate pathway in plant carnivory. Oikos 102:221-224.

Benzing, D. H. 1986. Foliar specialization for animal-assisted nutrition in Bromeliaceae. Pages 235-256 in B. Juniper and R. Southwood, editors. Insects and the plant surface. Edward Arnold, London, UK.

Benzing, D. H. 2000. Bromeliaceae: profile of an adaptative radiation. Cambridge University Press, Cambridge, UK.

Benzing, D. H., and K. M. Burt. 1970. Foliar permeability among twenty species of the Bromeliaceae. Bulletin of the Torrey Botanical Club 97:269-279.

Benzing, D. H., T. J. Givnish, and D. Bermudes. 1985. Absorptive trichomes in Brocchinia reducta (Bromeliaceae) and their evolutionary and systematic significance. Systematic Botany 10:81-91.

Benzing, D. H., K. Henderson, B. Kessel, and J. Sulak. 1976. The absorptive capacities of bromeliad trichomes. American Journal of Botany 63:1009-1014.

Benzing, D. H., and A. Renfrow. 1974. The mineral nutrition of Bromeliaceae. Botanical Gazette 135:281-288.

Ellis, A. G., and J. J. Midgley. 1996. A new plant-animal mutualism involving a plant with sticky leaves and a resident hemipteran insect. Oecologia 106:478-481.

Endres, L., and H. Mercier. 2001. Ammonium and urea as nitrogen sources for bromeliads. Journal of Plant Physiology 158:205-212.

Endres, L., and H. Mercier. 2003. Amino acid uptake and profile in bromeliads with different habitats cultivated in vitro. Plant Physiology and Biochemistry 41:181-187.

Fischer, R. C., W. Wanek, A. Richter, and V. Mayer. 2003. Do ants feed plants? A ${ }^{15} \mathrm{~N}$ labeling study of nitrogen fluxes from ants to plants in the mutualism of Pheidole and Piper. Journal of Ecology 91:126-134.

Givnish, T. J., E. L. Burkhardt, R. E. Happel, and J. D. Weintraub. 1984. Carnivory in the bromeliad Brocchinia reducta, with a cost/benefit model for the general restriction of carnivorous plants to sunny, moist, nutrient-poor habitats. American Naturalist 124:479-497.

Hurlbert, S. H. 1984. Pseudoreplication and the design of ecological field experiments. Ecological Monographs 54:187211.

Huxley, C. 1980. Symbiosis between ants and epiphytes. Biological Review 55:321-340.

Machado, G., and P. S. Oliveira. 2002. Maternal care in the neotropical harvestman Bourguyia albiornata (Arachnida: Opiliones): oviposition site selection and egg protection. Behaviour 139:1509-1524.

Oliveira, P. S., and R. J. Marquis. 2002. The cerrados of Brazil. Columbia University Press, New York, New York, USA.

Owen, T. P., Jr., and W. W. Thomson. 1988. Sites of leucine, arginine, and glycine accumulation in the absorptive trichomes of a carnivorous bromeliad. Journal of Ultrastructure and Molecular Structure Research 101:215-223.

Reich, A., J. J. Ewel, N. M. Nadkarni, T. Dawson, and R. D. Evans. 2003. Nitrogen isotope ratios shift with plant size in tropical bromeliads. Oecologia 137:587-590.

Rico-Gray, V., J. T. Barber, L. B. Thien, E. G. Ellgaard, and J. J. Toney. 1989. An unusual animal-plant interaction: feeding of Schomburgkia tibicinis (Orchidaceae) by ants. American Journal of Botany 76:603-608.

Romero, G. Q., and J. Vasconcellos-Neto. 2004a. Beneficial effects of flower-dwelling predators on their host plant. Ecology 85:446-457.

Romero, G. Q., and J. Vasconcellos-Neto. 2004b. Spatial distribution patterns of jumping spiders associated with terrestrial bromeliads. Biotropica 36:596-601.

Romero, G. Q., and J. Vasconcellos-Neto. 2005a. The effects of plant structure on the spatial and microspatial distribution of a bromeliad-living jumping spider (Salticidae). Journal of Animal Ecology 74:12-21.

Romero, G. Q., and J. Vasconcellos-Neto. 2005b. Population dynamics, age structure and sex ratio of the bromeliaddwelling jumping spider, Psecas chapoda (Salticidae). Journal of Natural History 39:153-163.

Romero, G. Q., and J. Vasconcellos-Neto. 2005c. Spatial distribution and microhabitat preference of Psecas chapoda (Peckham \& Peckham) (Araneae, Salticidae). Journal of Arachnology 33:124-134.

Rossa-Feres, D. de C., G. Q. Romero, E. Gonçalves-de-Freitas, and R. J. F. Feres. 2000. Reproductive behavior and seasonal occurrence of Psecas viridipurpureus (Salticidae, Araneae). Brazilian Journal of Biology 60:221-228.

Sagers, C. L., S. M. Ginger, and R. D. Evans. 2000. Carbon and nitrogen isotopes trace nutrient exchange in an ant-plant mutualism. Oecologia 123:582-586.

Sakai, W. S., and W. G. Sanford. 1980. Ultrastructure of the water-absorbing trichomes of pineapple (Ananas comosus, Bromeliaceae). Annals of Botany 46:7-11.

Sambrook, J., E. F. Fritsch, and T. Maniatis. 1989. Molecular cloning: a laboratory manual. Volume 1. Cold Spring Harbor Laboratory Press, Cold Spring Harbor, New York, USA.

Schlenck, F., and R. E. De Palma. 1957. The formation of Sadenosylmethionine in yeast. Journal of Biological Chemistry 229:1037-1057.

Schmitz, O. J., P. A. Hambäck, and A. P. Beckerman. 2000. Trophic cascades in terrestrial systems: a review of the effects of carnivore removals on plants. American Naturalist 155: $141-153$

Sokal, R. R., and F. J. Rohlf. 1995. Biometry: the principles and practice of statistics in biological research. Third edition. W. H. Freeman, New York, New York, USA.

Solano, P. J., and A. Dejean. 2004. Ant-fed plants: comparison between three geophytic myrmecophytes. Biological Journal of the Linnean Society 83:433-439.

Treseder, K. K., D. W. Davidson, and J. R. Ehleringer. 1995. Absorption of ant-provided carbon and nitrogen by a tropical epiphyte. Nature 357:137-139. 